\title{
Preface: Monitoring and modelling to guide coastal adaptation to extreme storm events in a changing climate
}

\author{
J. M. Brown ${ }^{1}$, P. Ciavola ${ }^{2}$, G. Masselink ${ }^{3}$, R. McCall ${ }^{3,4}$, and A. J. Plater ${ }^{5}$ \\ ${ }^{1}$ The National Oceanography Centre, Liverpool, UK \\ ${ }^{2}$ University of Ferrara, Ferrara, Italy \\ ${ }^{3}$ Plymouth University, Plymouth, UK \\ ${ }^{4}$ Deltares, Delft, the Netherlands \\ ${ }^{5}$ University of Liverpool, Liverpool, UK \\ Correspondence to: J. M. Brown (jebro@noc.ac.uk)
}

Published: 12 February 2016

\begin{abstract}
Storms across the globe and their associated consequences in coastal zones (flooding and erosion), combined with the long-term geomorphic evolution of our coastlines, are a threat to life and assets, both socioeconomic and environmental. In a changing climate, with a rising global sea level, potentially changing patterns in storm tracks and storminess, and rising population density and pressures on the coastal zone, the future risk of coastal storm impacts is likely to increase. Coastal managers and policy makers therefore need to make effective and timely decisions on the use of resources for the immediate and longer term.

Research focused on "monitoring and modelling to guide coastal adaptation to extreme storm events in a changing climate" is becoming more common; its goal is to provide science-based decision support for effective adaptation to the consequences of storm impacts, both now and under future climate scenarios at the coast. The growing transfer of information between the science community and end-users is enabling leading research to have a greater impact on the socioeconomic resilience of coastal communities. This special issue covers recent research activities relating to coastal hazard mapping in response to extreme events, economic impacts of long-term change, coastal processes influencing management decisions and the development of online decision support tools.
\end{abstract}

\section{Introduction}

A clearer picture of how coastal hazards may change in the future will enable coastal communities and industries to adapt effectively to a changing coastal environment to achieve resilience over the long term. Two current aims of the research community to help attain this goal are the following:

- to assess and provide levels of probability on the impacts of climate change at the coast;

- to increase our understanding of the consequences of extreme storm impacts to help provide evidence-based policy advice.

To enable regional-scale and long-term study of the changing patterns within a coastal system, modelling approaches are often adopted to simulate waves (e.g. De winter et al., 2012), water levels (e.g. Howard et al., 2014) and morphological evolution (e.g. Ashton et al., 2001). However, for the projections to be credible the monitoring of different coastal types is required to determine their validity, constrain the uncertainty in model predictions, and identify important processes and interactions that need to be captured within numerical or conceptual models.

Multidisciplinary research and stakeholder engagement are necessary to ensure improved understanding of coastal storm impacts is translated into effective planning for societal benefit (Pine, 2011). Multiple projects across Europe and the international science community are therefore currently focused on monitoring and/or modelling extreme events from 


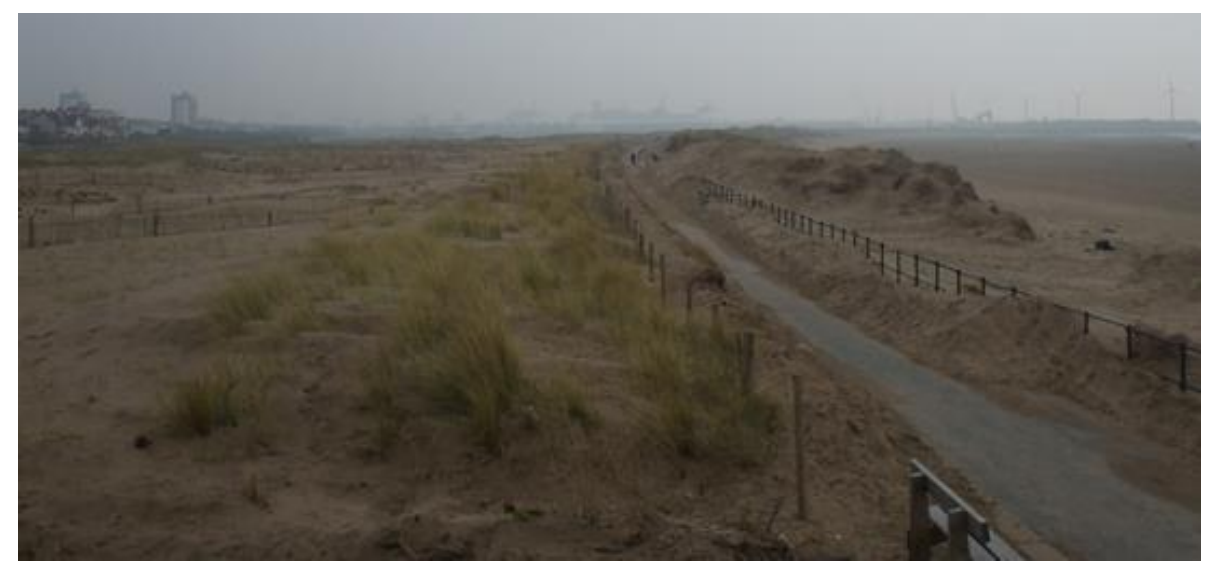

Figure 1. An example of a UK site (Crosby, North West England) where the dune system has built up around an engineered defence (the pathway runs along the top of a seawall and revetment) due to its position relative to the spring high-tide level, thereby changing the management issues in this location from flood risk to safe access.

all fields of study to improve future coastal resilience through working with the end-user community. More recently, the need for data assimilation into coastal impact models is being addressed in order to improve the capability of early warning systems (Van Dongeren et al., 2013; Sembiring et al., 2015). An example of how research can guide management decisions is in the improved understanding of a systems response to intervention through the development of transferable tools that incorporate leading scientific developments to reduce the uncertainty in alternative solutions and designs for sustainable long-term defence schemes (e.g. Fig. 1). Within this special issue, the risk posed by natural hazards in coastal environments is studied. Coastal vulnerability is shown to be the balance of a community's susceptibility and resilience. The research focuses on different communities vulnerable to physical processes during extreme events and increased flood risk under future sea level scenarios. Two key research areas are (1) early warning systems that run operationally to enable rapid response to imminently forecast storms; and (2) geographic information system (GIS) decision-support tools that are used to visualise erosion and flood risk to inform risk management frameworks and test mitigation measures. By understanding regional vulnerability appropriate land-use planning can facilitate evacuation pathways and improve the positioning of critical infrastructure.

In Sect. 2 of this preface there is a brief overview of each contribution to the special issue. This is followed by a summary of the research in Sect. 3.

\section{Research contributions}

The research in this special issue is not only focused on storm events themselves, but also the long-term changes and adaptation to flood hazard. We first introduce the impact studies followed by those looking at long-term trends in both physical coastal process and socioeconomic development.

\subsection{Storm impact studies at the event scale}

Sea state and surge forecasts are well developed, while capabilities to consider coastal response are still improving. This section focuses on the coastal impact of nearshore storms in a changing climate. The need for monitoring in conjunction with early warning systems to calibrate morphological response and assimilate real-time offshore conditions is demonstrated to improve hazard forecasting (Harley et al., 2016). The ability to respond to a storm forecast can greatly reduce loss of life as well as storm damage and, therefore, economic costs. To capture uncertainty in forecasts, modelling systems are often run in ensemble mode (Flowerdew et al., 2010). Methods to reduce the uncertainty in morphological forecasts are now also being developed (Harley et al., 2016). Early warning is not only about the ability to accurately forecast a storm event in a timely manner, but also about the behaviour of society in response to such a warning (Pescaroli and Magni, 2015). To implement effective warning systems, there must be an understanding of what the hazard is and where vulnerable areas are (Perini et al., 2016; Lapidez et al., 2015). Such information can be assessed using cost-distance analysis and knowledge of land use (Perini et al., 2016). Developing these tools requires high resolution monitoring to produce quality maps for end-users to identify regional vulnerability. Continued monitoring enables capability assessment for more extreme and less frequent events when they occur (Perini et al., 2016). This highlights the need to catalogue storm levels as they occur (as done by Wadey et al., 2015), which also provides a basis for establishing any antecedent conditions that contribute to increased coastal vulnerability (see also Dissanayake et al., 2015). The development of risk maps based on cost-distance analysis can be 
used to identify the cost-benefit ratio of different coastal defence systems (Perini et al., 2016). Incorporating such maps into decision-support tools (see Knight et al., 2015) enables assessment of the time variation of the flood hazard during storms, and in response to climate change, sea-level rise and future management intervention. Improved knowledge of pathways for flood water also improves evacuation planning (Perini et al., 2016; Lapidez et al., 2015) in preparation for early warning.

Both social and behavioural patterns influence the effectiveness of an early warning, not only due to the response, but also through the preparedness and communication of information. Improvements in education, training, and accountability are more critical than further development in technology (Pescaroli and Magni, 2015). To improve evacuation plans, vulnerability assessments of coastal communities are required. To carry out such assessment, plausible extremes have to be considered to enable a worst-case impact assessment from possible storm tracks that influence a region. This typically requires the use of large-scale modelling studies (Lapidez et al., 2015). Many models are often limited by the availability of high resolution and timely input data. The efficiency of models can also limit the amount of detail that can be considered to allow multiple ensembles of simulations. Methods must therefore be considered to ensure critical features that are important for accurate impact modelling, are appropriately incorporated and are not smoothed during data processing (Hodges, 2015). Such techniques are important for inundation modelling, as defences and infrastructure that limits the flow of water must be accurately resolved to generate an accurate flood map (Hodges, 2015). The accuracy of the mapping is not only important for knowledge of flood depths and velocities to identify the hazard rating of events, but also to enable managers to consider cost-benefit analysis of varied solutions to coastal flood and erosion risk. To support managers in planning more strategically, the development of decision-support tools, which incorporate a range of flood maps to cover plausible hazard scenarios, is becoming more common (Knight et al., 2015). Such tools are designed to meet the needs of the end-user, but incorporate the latest advances in scientific models to provide evidence to underpin management decisions. One difficulty in generating such tools beyond the scale of a local region is the lack of standardized monitoring to enable identical model applications to populate the tool in a uniform way at the national level (Knight et al., 2015).

To aid the event selection incorporated into decisionsupport tools and to test early warning systems, there needs to be better categorization of the extreme events that impact a region (Wadey et al., 2015) and better understanding of how repeated shocks to a system modify the vulnerability (Dissanayake et al., 2015). Authorities are more frequently collecting long-term observations to understand the coastal processes to inform policy making. Following an extreme event managers need to categorise the severity relative to historical conditions to enable impact assessments of both engineered and natural defence systems (Wadey et al., 2015). This enables better understanding of the critical conditions that trigger a change in a system's resilience. In the most extreme cases this change may be permanent, requiring a change in management policy (Knight et al., 2015). Early warning of when a system may reach a tipping point is thus required to plan long-term management strategies. Long-term national monitoring also enables better analysis of the occurrence (Wadey et al., 2015) and impacts (Dissanayake et al., 2015) of storm "clustering" in both time and space. Spatial impact is of great importance for a nation due to the socioeconomic impacts, while for local communities a continued impact within a short time frame is a more immediate concern as repeated shock interspersed with short recovery time can increase vulnerability to later events. In terms of natural defence, the repeat impact of storm waves can modify the beach-dune profile, changing the system's vulnerability (Dissanayake et al., 2015). However, the cumulative erosive impact is found to be insensitive to the event chronology.

\subsection{Long-term influence on coastal resilience}

Over the long term, other factors in addition to storm conditions also need consideration to accurately assess changes concerning flood and erosion hazard. Rising sea level needs to be considered in assessments of extreme events (Wadey et al., 2015), while changes in coastal land use and infrastructure need consideration in assessment of the impact of events (Fakhruddin et al., 2015; Stevens et al., 2015; Sekovski et al., 2015). In support of proactive long-term adaptive management, guidance on suitable frameworks to apply when considering climate change is also required (Armstrong et al., 2015).

Coastal urbanization (Stevens et al., 2015; Sekovski et al., 2015) and modern life style, such as commuting to work, are placing people in a hazard zone, even if temporarily. The infrastructure that supports these coastal communities is also at risk (Fakhruddin et al., 2015). Analysis of the temporal variability in floodplain population and infrastructure vulnerability is therefore required to inform adaptive management. Transferable methods can be used to assess changes in risk in response to residential population growth relative to sea-level rise (Stevens et al., 2015), and to assess the change in hazard for chosen storm levels in response to different types of urban growth (Sekovski et al., 2015). It is suggested that population growth is a greater contributor to increased flood risk than sea-level rise (Stevens et al., 2015) and that a "compact" growth type increases the flood hazard over other modes of urbanization (Sekovski et al., 2015). To assess the susceptibility of a community's infrastructure, both the physical exposure and the repair capacity need to be considered in vulnerability indicator models as developed by Fakhruddin et al. (2015). 
With urbanization and rising sea levels, coastal squeeze is becoming a greater threat to natural habitats. Ecosystem adaptation is therefore being considered more often as a mechanism to increase a system's resilience (Brown et al., 2011). One example of such a solution is coastal wetlands, which are recognized for their ability to lessen storm impacts and absorb flood water (Smolders et al., 2015). In response to economic growth within a changing coastal climate alternative solutions to flood and erosion risk management are emerging. At the same time, the environmental impact of an approach is now recognized as important and "softer" solutions are being considered (Smolders et al., 2015).

To manage the long-term coastal adaptation a hybrid of three principal approaches (Scenario-Led, Vulnerability-Led and Decision-Centric) is often applied (Armstrong et al., 2015). As understanding of climate change increases, practical guidance on how to respond needs to be addressed to ensure effective long-term management. This is particularly important at sites of coastal industry that have long life expectancies, e.g. the nuclear energy sector (see also Knight et al., 2015). Conflicting coastal interests often complicate coastal management, preventing a uniform approach across a region, although numerous interactions and feedbacks exist (Armstrong et al., 2015).

\section{Summary}

With rising sea levels, increasing economic costs, expanding populations within low-lying coastal regions, and defence degradation, coastal flood and erosion risk are increasing. It is not only lives, livelihoods and human health that are at risk, but also infrastructure, business and ecosystems. To enable sustained development socioeconomic analysis must be incorporated with oceanographic and geomorphic process studies to improve risk management frameworks and understand the fragility of natural, engineered and human-altered systems. Although there is great uncertainty associated with projected changes in storminess, it is known higher sea levels will increase the impact of present-day storms as elevated water levels enable ageing defences to be more easily overtopped and dune retreat to increase. This special issue demonstrates a good understanding of the joint probability of water levels and waves that cause coastal impacts are therefore needed. The impacts of waves, surge and their interactions are becoming more hazardous for many coastal systems, whether engineered, gravel, sand, estuarine, wetland or cliff coastlines. By combining modelling with monitoring schemes, a robust and reliable understanding of coastal dynamics can provide credible evidence for decision support in response to coastal hazards. The research presented within this special issue demonstrates recent developments and limitations in inundation modelling, morphological response modelling, storm cluster analysis and development of socioeconomic decision-support tools to better communi- cate risk and vulnerability to coastal communities. Through the improved understanding and awareness of storm impacts these studies aim to enable timely adaptation measures and resource allocations to be made strategically within management plans. However, practical guidance on best-practise approaches for long-term adaptive management is still needed.

Acknowledgements. The work described in this publication was brought together under the efforts of the EPSRC funded ARCoES project (grant no. EP/1035390/1), NERC National Capability funding to the NOC Marine Physics and Ocean Climate research directorate and the EPSRC Impact Accelerator Account funding to Liverpool University. P. Ciavola acknowledges support from the RISCKIT project (EU contract 603458) and R. McCall would like to acknowledge funding by the EPSRC thought the NUPSIG project (grant no. EP/H040056/1) and Deltares (Strategic Research Programme 1209342).

\section{References}

Armstrong, J., Wilby, R., and Nicholls, R. J.: Climate change adaptation frameworks: an evaluation of plans for coastal Suffolk, UK, Nat. Hazards Earth Syst. Sci., 15, 2511-2524, doi:10.5194/nhess-15-2511-2015, 2015.

Ashton, A., Murray, B., and Arnauly, O.: Formation of coastline features by large-scale instabilities induced by high angle waves, Nature, 414, 296-299, 2001.

Brown, S., Nicholls, R. J., Vafeidism A., Hinkel, J., and Watkiss, P.: The Impacts and Economic Costs of Sea-Level Rise in Europe and the Costs and Benefits of Adaptation. Summary of Results from the EC RTD ClimateCost Project, in: The ClimateCost Project, Final Report, Vol. 1: Europe, edited by: Watkiss, P., Stockholm Environment Institute, Sweden, 44 pp., 2011.

De Winter, R. C., Sterl, A., de Vries, J. W., Weber, S. L., and Ruessink, B. G.: The effect of climate change on extreme waves in front of the Dutch coast, Ocean Dynam., 62, 1139-1152, 2012.

Dissanayake, P., Brown, J., and Karunarathna, H.: Impacts of storm chronology on the morphological changes of the Formby beach and dune system, UK, Nat. Hazards Earth Syst. Sci., 15, 15331543, doi:10.5194/nhess-15-1533-2015, 2015.

Fakhruddin, S. H. M., Babel, M. S., and Kawasaki, A.: Assessing the vulnerability of infrastructure to climate change on the Islands of Samoa, Nat. Hazards Earth Syst. Sci., 15, 1343-1356, doi:10.5194/nhess-15-1343-2015, 2015.

Flowerdew, J., Horsburgh, K., Wilson, C., and Mylne K.: Development and evaluation of an ensemble forecasting system for coastal storm surges, Q. J. R. Meteorol. Soc., 136, 1444-1456, 2010.

Harley, M. D., Valentini, A., Armaroli, C., Perini, L., Calabrese, L., and Ciavola, P.: Can an early-warning system help minimize the impacts of coastal storms? A case study of the 2012 Halloween storm, northern Italy, Nat. Hazards Earth Syst. Sci., 16, 209-222, doi:10.5194/nhess-16-209-2016, 2016.

Hodges, B. R.: Representing hydrodynamically important blocking features in coastal or riverine lidar topography, Nat. Hazards Earth Syst. Sci., 15, 1011-1023, doi:10.5194/nhess-15-10112015, 2015. 
Howard, T., Pardaens, A. K., Bamber, J. L., Ridley, J., Spada, G., Hurkmans, R. T. W. L., Lowe, J. A., and Vaughan, D.: Sources of 21st century regional sea-level rise along the coast of northwest Europe, Ocean Sci., 10, 473-483, doi:10.5194/os-10-473-2014, 2014.

Knight, P. J., Prime, T., Brown, J. M., Morrissey, K., and Plater, A. J.: Application of flood risk modelling in a web-based geospatial decision support tool for coastal adaptation to climate change, Nat. Hazards Earth Syst. Sci., 15, 1457-1471, doi:10.5194/nhess-15-1457-2015, 2015.

Lapidez, J. P., Tablazon, J., Dasallas, L., Gonzalo, L. A., Cabacaba, K. M., Ramos, M. M. A., Suarez, J. K., Santiago, J., Lagmay, A. M. F., and Malano, V.: Identification of storm surge vulnerable areas in the Philippines through the simulation of Typhoon Haiyan-induced storm surge levels over historical storm tracks, Nat. Hazards Earth Syst. Sci., 15, 1473-1481, doi:10.5194/nhess-15-1473-2015, 2015.

Pescaroli, G. and Magni, M.: Flood warnings in coastal areas: how do experience and information influence responses to alert services?, Nat. Hazards Earth Syst. Sci., 15, 703-714, doi:10.5194/nhess-15-703-2015, 2015.

Perini, L., Calabrese, L., Salerno, G., Ciavola, P., and Armaroli, C.: Evaluation of coastal vulnerability to flooding: comparison of two different methodologies adopted by the EmiliaRomagna region (Italy), Nat. Hazards Earth Syst. Sci., 16, 181194, doi:10.5194/nhess-16-181-2016, 2016.

Pine, J. C.: Enhancing the Resilience of Coastal Communities: Dealing with Immediate and Long-Term Impacts of Natural Hazards, in: Chapter 12.13 In Treatise on Estuarine and Coastal Science, edited by: Wolanski, E. and McLusky, D., Academic Press, Waltham, 271-288, 2011.
Sekovski, I., Armaroli, C., Calabrese, L., Mancini, F., Stecchi, F., and Perini, L.: Coupling scenarios of urban growth and flood hazards along the Emilia-Romagna coast (Italy), Nat. Hazards Earth Syst. Sci., 15, 2331-2346, doi:10.5194/nhess-15-23312015, 2015.

Sembiring, L., van Ormondt, M., van Dongeren, A., and Roelvink, D.: A validation of an operational wave and surge prediction system for the Dutch coast, Nat. Hazards Earth Syst. Sci., 15, 12311242, doi:10.5194/nhess-15-1231-2015, 2015.

Smolders, S., Plancke, Y., Ides, S., Meire, P., and Temmerman, S.: Role of intertidal wetlands for tidal and storm tide attenuation along a confined estuary: a model study, Nat. Hazards Earth Syst. Sci., 15, 1659-1675, doi:10.5194/nhess-15-1659-2015, 2015.

Stevens, A. J., Clarke, D., Nicholls, R. J., and Wadey, M. P.: Estimating the long-term historic evolution of exposure to flooding of coastal populations, Nat. Hazards Earth Syst. Sci., 15, 12151229, doi:10.5194/nhess-15-1215-2015, 2015.

Van Dongeren, A., Van Ormondt, M., Sembiring, L., Sasso, R., Austin, M., Briere, C., Swinkels, C., Roelvink, D., and Van Thiel de Vries, J.: Rip current predictions through model data assimilation on two distinct beaches, Proceedings of the 7th International Conference on Coastal Dynamics, Bordeaux, France, 1775-1786, 2013.

Wadey, M. P., Brown, J. M., Haigh, I. D., Dolphin, T., and Wisse, P.: Assessment and comparison of extreme sea levels and waves during the 2013/14 storm season in two UK coastal regions, Nat. Hazards Earth Syst. Sci., 15, 2209-2225, doi:10.5194/nhess-152209-2015, 2015. 